Submitted: 27 April 2021 | Accepted in revised version: 22 December 2021| Published: 30 December 2021

\title{
Social capital as a determinant for raising ecosystem services awareness - an application to an Albanian pastoral ecosystem
}

\begin{abstract}
This paper aims to map the ecosystem services (ES) provided by a reputed agropastoral ecosystem in the south of Albania and ascertain whether social capital affects the level of importance attributed to them. A perception analysis of both buyers and sellers of ES within the pastoral ecosystem is undertaken. The pastoral ecosystem is mainly evaluated for cultural services such as tradition, enhancing the area's image, and environment ES. The strong inclination towards cultural ES and socioeconomic services indicates a lack of awareness of both buyers and sellers of ES in the local community regarding the environmental aspects of their ecosystem. However, participants showing a higher radius of trust with high linking social capital are more likely to confer very high importance to environmental services. Similarly, the cultural ES (traditional aspect) of the pastoral ecosystem is affected by cognitive and structural social capital. These are interesting findings for public policymaking concerning the opportunity to develop market transaction ES. Its development is more ground-based and effective if participation and civic engagement, especially the Linking dimension, is enhanced in the pastoral community.
\end{abstract}

\section{Keywords:}

pastoral ecosystem services, social capital, linking, ecosystem services

mapping, Albania
Elena Kokthi ${ }^{1 *}$, Elda Muçoº, Mélanie Requier-Desjardins ${ }^{3}$, Fatmir Guri ${ }^{4}$

1) Agriculture University of Tirana, Department of Biotechnology and Food, Tirana, Albania

2) University of Paul Valery, Department of Geography and Management, Montpellier, France

3) Center of Agronomic Mediterranean Studies, UMR SENS, Montpellier, France

\footnotetext{
${ }^{4)}$ Agriculture University of Tirana, Department of Economy and Rural Policy Development, Tirana, Albania

*Corresponding author: Elena Kokthi, Agriculture University of Tirana, Department of Biotechnology and Food, Rruga Pajsi Vodica 1001, Tirana, Albania, Email: ekokthi@ubt.edu.al
} 


\section{Introduction}

In developing countries, pastoralists are persistently left out of rural development programmes even though the rangelands produce several tangible and no intangible Ecosystem Services (ES). This is mainly the result of a weak social fabric identifying, valorising, and introducing the ES in development strategies (Milder et al., 2010). For as long as people have managed natural resources, they have engaged in collective action; however, development programmes have paid too little attention to how social and human capital affects the environment (Pretty \& Ward, 2001). The concept of ES has become an essential model for linking the functioning of ecosystems to human welfare (Fisher et al., 2009). For that reason, ES has gained in popularity as a tool to communicate the significance of ecosystems to policymakers (Barnaud et al., 2018; Ishihara, 2018; Pascual et al., 2014). ES is generally defined as "the benefits which people derive from nature, or more precisely as "the aspects of ecosystems, utilised actively or passively, to produce human well-being' (Ibid.). The ES framework is the ground of the payment for Ecosystem Services (PES), a significant scheme that allows the retribution of communities that produce useful ES. Support for PES programs stems from their ability to promote the conservation of nature and the supply of ES through incentives, thus providing social and ecological benefits (Gómez-Baggethun et al., 2010). Several studies indicate that PES could provide significant livelihood benefits to poor people at the household or community level, whether in the form of cash payments or non-cash benefits such as enabling the transition to more profitable and resilient land-use systems, establishing secure land tenure or strengthening social capital and support local institutions (Amézquita et al., 2004; Antle \& Diagana, 2003; Antle \& Stoorvogel, 2008; Dumont et al., 2019; Graff-Zivin \& Lipper, 2008; Milder et al., 2010)

Extensive agropastoral ecosystems are recognised as socio-ecological systems (SES) characterised by their potential for providing ES, such as food and fibre (Huntsinger \& Oviedo, 2014). Traditional pastoral rangeland management practices, such as the use of seasonal grassland reserves and livestock mobility, influence vegetation composition, coverage and abundance in rangelands, offer tools for biomass and soil carbon restoration, all of which contribute to the mitigation of climate change (Amézquita et al., 2004; Dumont et al., 2019; McGrath et al., 2018; Seid et al., 2016; Tamou et al., 2018). The ES provided by pastoral ${ }^{1}$ systems ${ }^{2}$ are globally acknowledged for its food and ecological services and the human populations they support, especially in developing countries (Antle \& Diagana, 2003; Antle \& Stoorvogel, 2008; Dong, 2016; Dong et al., 2011; McGrath et al., 2018). Kokthi et al., 2016; Kokthi \& Kruja, (2017b) found that the mountainous origin and cultural values, such as tradition and heritage on specific pastoral areas, substantially impact the consumer's willingness to pay (WTP) for a typical pastoral product. Positive perceptions about traditional grazing are linked to the higher quality of pastoral products in the marketplace (Imami et al., 2016; Kokthi et al., 2016, 2021; Kokthi \& Kruja, 2017a).

Also, pastoral ecosystems represent a potential domain for agroecological transitions application in agricultural ecosystems, and its development relies on multiple stakeholders' innovation capacities (Berthet et al., 2016). The transition is particularly relevant within the Farm to Fork Strategy, which is at the heart of the European Green Deal ${ }^{3}$ that aims to make food systems fair, healthy and environmentally friendly. Developing countries such as Albania and other Balkan Countries will struggle to adopt the emerging green measures; for these reasons, local actors perceptions relating to pastoral ecosystems and the ES offered by them is crucial in the transition process.

Pastoral ecosystems are home to various plants, animals and microorganisms of ecological, economic, and socio-cultural importance. Several studies developed explicitly for the Sub-Saharan regions of Africa in the 1990s have shown how pastoralism, as both a

\footnotetext{
1 Pastoralism is a livelihood system based on extensive livestock production and pastoral community concept used in this paper make reference not only to the breeders but also to other local actors linked directly and indirectly with the pastoral activity

2 Pastoral systems, hunting-gathering (including fishing), and "sylvo-transhumance" are the main production systems within arid and semi-arid lands. Pastoral systems can be grouped under two main types: transhumant, and agropastoral (FAO, definition). In the present study is considered the agropastoral type.

3 The European Green Deal is a set of policy initiatives by the European Commission with the overarching aim of making Europe climate neutral in 2050/ https://ec.europa.eu/info/strategy
} 
way of life and style of cattle management, is vital for the sake of the natural environment Assouma et al., 2019; Bigando \& Charbonneau, 2017; Niamir-Fuller et al., 2012; Scoones \& Graham, 1994). Pastoralists employ several techniques to manage rangeland resources and possess traditional ecological knowledge (TEK), which could be valuable in assessing, conserving and utilising rangeland biodiversity (Seid et al., 2016; Tamou et al., 2018). Pastoral ecosystems offer an essential contribution to particular landscapes with an important cultural value. The scenic beauty and other aesthetic experiences, such as perceived care, attachment, and identity or a sense of place (Huntsinger \& Oviedo, 2014), are linked to different extensive pastoral ecosystems identified within standard denominator bases social capital (SC). Consistent lack of focus on evaluating and fostering social capital in interaction with the PES design and its outcomes persists (Hejnowicz et al., 2014). However, studies show that social capital is positively correlated with improvement in development outcomes in watersheds (Krishna \& Uphoff, 1999) on positive biodiversity conservation outcomes (Thuy et al., 2011) (Alló et al., 2013), water conservation maintenance and infrastructure (Bouma et al., 2008). Communities with strong social links and networks can be more conducive to incentive-based schemes, such as PES (Cranford \& Mourato, 2011). Barnes-Mauthe et al. ( 2015) show the positive relationship between $\mathrm{SC}$ and ES and consider SC itself an ES.

Moreover, Notaro \& Paletto (2011a) show that a greater sense of local identity and SC in alpine communities is linked to greater environmental attention. This study will consider the SC concept a potential path to understand the possibility of future PES introduction into the Albanian policy agenda and other similar developing countries. We suggest that using the SC lens to analyse local people's perceptions of ES allows understanding the diversity and complexity of ecological processes underlying human activities in a pastoral ecosystem. Following this logic, this research aims to map the importance of the ES provided by a reputed agropastoral ecosystem in the south of Albania and, secondly, to analyse whether there is an interaction between the importance attributed to ES and local social capital. Two research questions (RQ) are proposed to achieve these objectives:
(RQ 1) Is the pastoral community of Gjirokastra aware of the provision of ES, and what type of ES, environmental or cultural, are more significant to local actors?

(RQ 2) What component of social capital influences perceptions about ES?

\section{Material and method}

\subsection{Methodological approach}

ES evaluation is not well developed in Albania. Although the study area represents an important traditional pastoral region, no exhaustive study has identified the main ES. Considering the shortcomings of the existing studies on ES in Albania, we have suggested for this study an iterative evaluation process based on stakeholder involvement. Scholars consider stakeholder involvement an appropriate tool to relate ecosystem "functions" to human well-being because they can help to: identify relevant ES, provide ground truths for the development of management options, and assign weights of importance to different ES (Raymond et al., 2014; Seppelt et al., 2011).

In the context of this study, we use a deliberative approach because local communities are entitled to a more accurate view of the cultural, socio-ecological, and economic representation of their pastoral ecosystem. Adapting the four types of ES buyers/sellers from Jenkins et al. (2004), the following stakeholders' segments were included in the interview process: 1 ) the public sector segment, 2) the private sector buyers, 3) suppliers or potential sellers of pastoral ES, 4) the consumers. The public sector segment comprises ES buyers seeking the protection of ES and the potential development of PES. It includes local, regional, and national governments (local and central authorities representants working in the study area are interviewed). Concerning the second segment, the private sector buyers segment, these buyers may purchase ES to support their business operations, for example, tour operators linking their tourism product with the image of the pastoral area. The third segment addressed by the study is composed of suppliers or potential sellers of pastoral 
ES, breeders and cheese producers. Thus the third segment consists of pastoralists (see sampling design). The fourth segment concerns the consumers who buy products from the pastoral ecosystem by expressing a higher WTP (Kokthi et al., 2016; Kokthi \& Kruja, 2017b). These studies showed that the expressed WTP for Gjirokastra typical cheese is linked to the product's safety because pesticides are not used in the pastoral area. Pesticide absence in food products is used as a proxy for food safety for the food basket in general in Albania, even though lack of pesticides is not a synonym of food safety (Kokthi et al., 2015). Consequently, considering that the consumer segment has already been analysed, it will not be the present study's focus.

\subsection{SC as a condition for PES scheme elaboration and the exploration of ES importance/ perceptions}

PES schemes' successful implementation and governance are linked to the various dimensions of value that different groups can share within society about the natural environment (Kenter et al., 2015; Reed et al., 2017). In this regard, Milder et al. (2010) suggest that local institutions can demystify PES and help communities address related challenges by facilitating collective action. Institutional effectiveness, system stability, and the mechanisms of collective and coordinated action underline the theoretical relevance of SC. In this regard, Putnam (2000) indicates that communities with an essential stock of SC will have a positive development trajectory for several reasons: 1) networks of civic engagement (CE) foster norms of generalised reciprocity and 2) encourage the emergence of social trust, 3) facilitate coordination and communication, 4) amplify reputations, and 5) embody past collaborative success, which can serve as a cultural template for future collaboration. In Putnam's social capital discourse, CE is the central pillar of SC because it is considered the primary source of trust generation.

Similarly, social trust and CE are strongly correlated; the greater the density of associational membership in a society, the more trusting its citizens. Therefore, trust and $\mathrm{CE}$ are two facets of the same underlying factor, SC; with no CE in place, it will be challenging to generate trust (Brehm \& Rahn, 1997; Putnam, 2000;
Welter, 2012). While trying to clarify SC's definition, scholars distinguish between two forms of SC, cognitive and structural (Alvarez \& Romai, 2017; E. Villalonga-Olives \& I. Kawachi, 2017; Krishna \& Uphoff, 1999; Villalonga-Olives et al., 2016). Cognitive SC is operationalised through interpersonal trust, reciprocity, and sharing. At the same time, structural SC is assessed through the density of social networks. Another way to present SC is through their horizontal and vertical direction. Helliwell \& Putnam (1995) and Putnam (2000) found that through horizontal $\mathrm{SC}$ in the form of bonding and bridging, individuals are oriented within the group, creating strong ties that result in homogenous groups connecting family members, close friends, and colleagues. While bridging SC designates inclusive interactions with other groups, it can strengthen the ties that link different ethnic and occupational backgrounds, including formal and informal social participation. Another component of SC is the vertical dimension, referred to as linking. Linking is based on hierarchical or unequal relations due to power, resources, and status differences. Linking is a more vertical relationship between those within and outside a community, such as between community members and external government workers (McGrath et al., 2018). Several scholars have made an effort to understand the value of SC when referring to a broader human interaction area such as a region or territory (Callois, 2004; Callois \& Aubert, 2007). Trust is perceived as the direct outcome of SC helping to foster local and territorial development (Callois, 2004). The researchers mentioned earlier suggest that regions whose inhabitants have significant SC will be more successful in achieving their objectives.

In the present study, cognitive SC and structural SC are considered. The assumption made in this research is that the greater the sense of traditions and $\mathrm{SC}$ in the pastoral community of Gjirokastra (Albania, see the study area presentation), the greater the attention paid to environmental ES. Individuals with a higher level of SC will have a greater tendency to assign higher importance to ES linked to the environment. We will also explore whether trust impacts the importance score assigned to the identified ES in the research area. In the following paragraphs is presented the operationalisation of SC indicators. 


\subsection{Study design}

The study is developed in a two-step iterative process. The first step analyses the perceptions of ES around the pastoral area of Gjirokastra Cheese through open questions of the five stakeholder groups explained below. Four questions were posed: 1) What environmental functions does pastoralism offer? 2) What services/products does pastoralism offer? 3) Who benefits from these goods, and is there a cost to them? 4) What are the risks associated with these services/products? In this first step, several ES have been identified and validated according to the importance score assigned by the producers of pastoral ES. For the second step, a closed structured questionnaire was applied.

The questionnaire was organised into three sections. The first collect the demographic data of breeders and cheese producers, while in the second section, the participants have attributed an importance score to each of the ES identified in the first step (from the open interviews). An explanation is offered to the participants as to the nature of an ecosystem and ES, with the following question directed: According to your best knowledge, what is the level of importance in your pastoral ecosystem of a specific service (example, fire prevention service) from one to five? $A$ response of one indicates that the ES is not important, and five suggests that it is very important. Eleven ES were identified from the open interviews, five of which are related to the environment and six to cultural and socio-economic services. As mentioned earlier, in the second step of the study, breeders and cheese producers have assigned an importance level to each. This step will not be used only as a validation step of the ES offered by the pastoral ecosystem of Gjirokastra but also to identify the level of importance ES suppliers' attribute to each. The analysis of the level of importance is based on a five-point Likert scale (Albaum, 1997). The participants assigned their level of importance ranging from not at all important $=1$ to very important $=5$ ) in response to the statements listed in Table 1.

The third section of the questionnaire is linked to SC, in which CE and trust indicators have been considered. As previously mentioned, SC indicators will be used to extrapolate the potential of ES development from an institutional perspective. Structural SC-CE (see Table 2 for CE indicator details) and cognitive $\mathrm{SC}$ indicators have been considered. Both indicators were adapted from the World Bank SC Tool (Krishna \& Uphoff, 1999). In the cognitive SC category, three trust indicators were explored. We have not opted to ask the widely used generalised trust (SC-Trust 1) "Generally speaking, how much do you believe in others", but instead ask a scenario type question. The wording of the questions related to trust is as follows: If you had to leave the village for some time, who would you ask to take care of your farm? 1) Family members (parents, brother, sister); 2) Neighbours; 3) Anyone from the village or neighbourhood. For the analysis, we refer to it as Trust 1 . Trust in institutions through- SC-Trust 2- In your opinion, will the economic and political situation of the country get better or worse? 1) will improve); 2) will deteri-

Table 1. Ecosystem services (ES) from the perspective of stakeholders.

\begin{tabular}{|l|l|}
\hline ES & ES description \\
\hline deforestation & Pastoral activities increase deforestation \\
\hline biodiversity & Pastoral services have a positive impact on biodiversity conservation \\
\hline pollution & Pastoral services increase pollution in the area \\
\hline fire prevention & Pastoral services can prevent fires in the summer \\
\hline carbon sequestration & Good management of pastoral services increases carbon sequestration \\
\hline local tradition & Pastoral services help to maintain tradition in the area \\
\hline local image & Pastoral services enhance the reputation and good image of the area \\
\hline income & Pastoral services generate income in the area \\
\hline tourism & Pastoral services provide essential input to tourism development \\
\hline employment & Pastoral service development employs in the area \\
\hline added value products & Pastoral services provide high value-added products for the market \\
\hline
\end{tabular}


orate; 3) do not know. For the analysis, we name it Trust 2, SC-Trust 3-Do you believe that the current government can improve SC-Trust 3-Do you believe the current government can improve its economic situation? 1) will improve); 2) will deteriorate; 3) do not know. Thus, Trust 1 will be used as a proxy for generalised trust and to define the radius of trust, while the other questions will be used to explore trust in institutions. The SC-CE indicators were worded as follows: Have you been approached by someone personally during the last three years who asked you to do any of the following?

\subsection{Sample design}

The open interviews were undertaken with participants from the municipality of Gjirokastra. Twenty-five open interviews were conducted. Five open interviews were developed in each of the following sectors: 1) agriculture within the municipality; 2) business (tourist agencies and hospitality operators); 3) non-governmental organisations (NGOs) and academia, particularly participants dealing with pastoral activities, livestock production, and environmental aspects of the pastoral ecosystem; 4) breeding and

Table 2. Description of Civic Engagement (CE) indicators

\begin{tabular}{|l|l|}
\hline ID & Description \\
\hline CE1 & Voted in elections \\
\hline CE2 & Participated in political, economic, and/or environmental associations \\
\hline CE3 & Made the media interested in a problem \\
\hline CE4 & Actively participated in an information campaign \\
\hline CE5 & Taken part in a protest march or demonstration \\
\hline CE6 & Make a monetary or in-kind donation to help people in difficulty \\
\hline CE7 & Contributed to a collective investment in your community \\
\hline CE8 & Volunteered for a charitable organisation \\
\hline CE9 & Taken part in a sit-in or disruption of government meetings/offices \\
\hline CE10 & Made a personal contact with an influential person (linking) \\
\hline
\end{tabular}

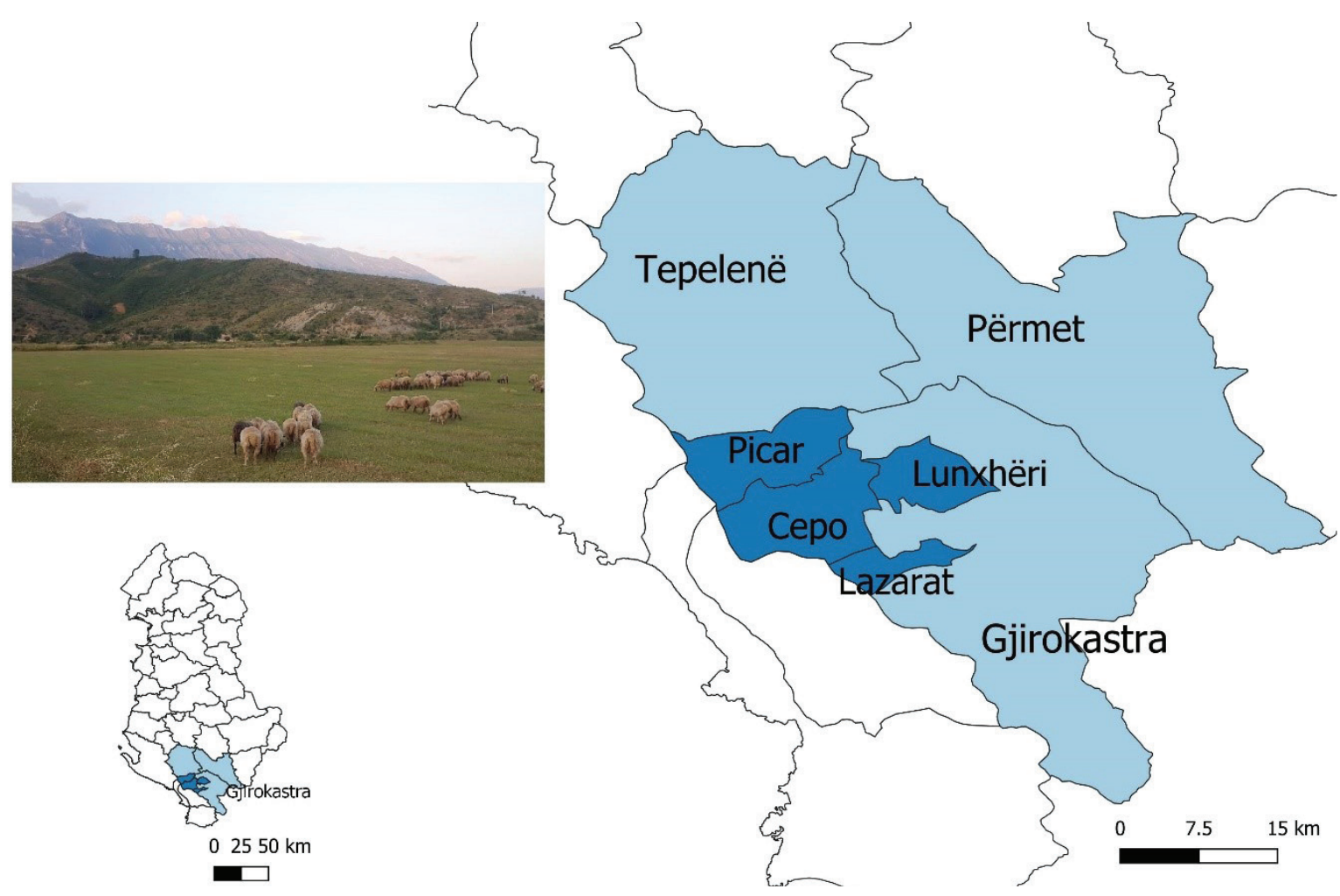

Figure 1. Geographical location of the study area within the Albanian state. 
cheese production participants; and 5) public policy sector dealing with agriculture and the environment (Ministry of Agriculture and Rural Development and Ministry of Environment in Albania).

The interviews conducted with breeders and cheese producers took place in four administrative units of the municipality of Gjirokastra (Figure 1).

Random sampling was applied through a two step-cluster procedure. Cluster sampling was performed as follows: the population of the Gjirokastra is divided into four clusters named 1 . Cepo, 2. Lazarat, 3. Picari, and 4. Lunxheri. These clusters represent the most important cheese production units of the Gjirokastra region due to the number of breeders and producers. These units were also selected because they represent the most important units in the region for breeding and cheese production, mainly in hilly and mountainous areas (Figure 1).

Next, two-stage sampling was applied, with a subset of respondents within selected clusters randomly selected and then included in the sample. One hundred one structured interviews were carried out of 91 breeders and ten cheese producers. 40\% of the interviews were completed in Cepo, $23 \%$ in Lazarat, $19 \%$ in Lunxheri, and $18 \%$ in Picar. The participants corresponded to the following age groups: about $33 \%$ were $24-45$ years old, $52 \%$ were $45-60$, and $15 \%$ were over 60 years old, representing the group ages living in rural Albania. Concerning their education level, about $51 \%$ of the respondents had completed school (12 years), $42 \%$ had a lower level (up to 8 years), and $7 \%$ had a university degree. The following sections will discuss the level of education, age, profession, geographical location, and perceptual mapping on the ES.

\subsection{Social capital and ES perceptions regression analysis}

As previously mentioned, it is assumed that attention to the environment and PES implementation also requires an important stock of SC. In that regard, we have explored the interaction between the SC and ES importance scores. The ordinal regression method is used to model the relationship between ES importance scores and a set of explanatory variables. Our dependent variable (ES importance scale) is an ordinal outcome with five levels $(1,2,3,4,5)$; five logits will be modelled, one for each cut point.

Let $\mathrm{fi}(\mathrm{xi})$...fk (xk) denote the response probabilities at values for a set of explanatory variables. Cumulative probabilities are formed as follows:

$F k=P(Y<k / x i)=f i(x i)+\ldots f k(x i), k=1,2 \ldots . k-1$

Cumulative logits are then formed as follows:

Lk=Logit (Fk (xi) $=\log (, k=1,2 \ldots . . K-1$ Letting $L k(x i)=\log -$ it [(Fk (xi)], where Fk (xi) is the cumulative probability up to, and including, category k, the proportional Odds model (McCullagh \& Nelder, 1989) can be expressed as follows :Lk $(x i)=\alpha k+\beta k(x i), k=1,2 \ldots . k-1$

The $\alpha$ parameters are the intercepts of cut points. The parameter vector $\beta$ expresses the regression coefficients for the covariate vector xi. This model's inherent proportional odd assumption states that the cumulative odd ratio for any two covariate values is constant across response categories. The interpretation of the estimates is as follows: for $\beta>0$, the odd ratio $e^{-\beta}<1$, meaning that higher cumulative scores are more likely than lower ones, for $\beta=0$, the odd ratio $e^{-\beta}=1$ suggests that high cumulative scores are equally likely to low cumulative scores and, finally, for $\beta<0$ the odd ratio $e^{-\beta}>1$ lower cumulative scores are more likely than higher cumulative scores.

The model that was tested is as follows:

\section{$\mathrm{Y}($ ES Importance score $)=\alpha+\beta_{1}$ Age $+\beta_{2}$ Education $+\beta_{3}$ Trust1 $+\beta_{4}$ Trust $2+\beta_{4}$ Trust3 $+\beta_{5}$ CE+e}

$R^{2}$ Nagelkerke (1991) coefficient of determination shows that the considered explanatory variables explain an important variation in all computed models. The test of parallel lines is also presented. The null hypothesis tested here is that the corresponding regression coefficients are equal across all levels of the response variable.

\section{Results}

The present research shows that $90 \%$ of respondents (respondents from the five sectors, see sample design) think that pastoral activity has an important impact on the environment(either positive or negative). About $80 \%$ argue that the well-managed ac- 


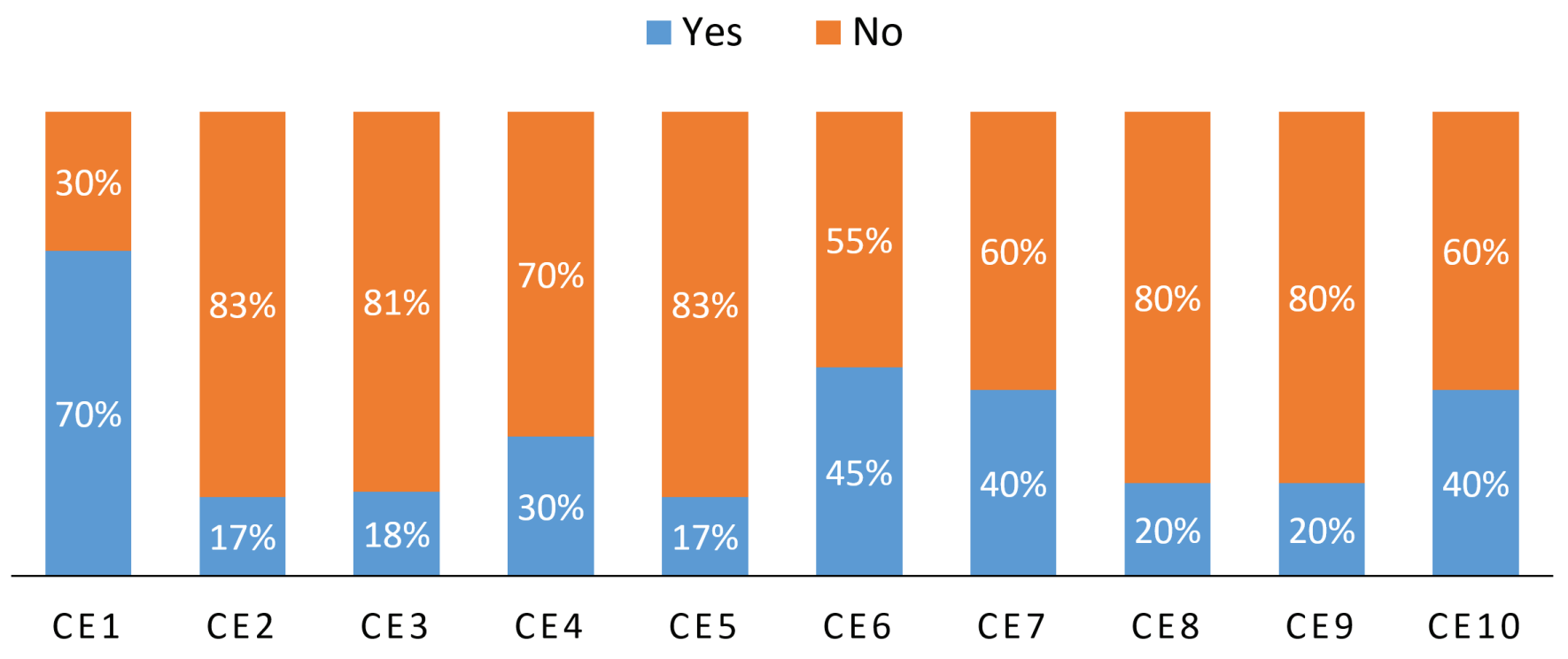

Figure 2. CE indicator valuation.

tivity will have a positive outcome. An analysis of the open interviews on the ES provided by pastoral ecosystem stakeholders show contradictory results. $50 \%$ of respondents (representing the public sector nationally and locally) noted that pastoral activity is responsible for deforestation and air pollution. In contrast, the other $50 \%$ representing the business sector and pastoralists, claim that pastoral activity is responsible for fire prevention, biodiversity conservation, and carbon sequestration. $80 \%$ consider the following to be very important: pastoral activities support the continuity of the tradition in the area, safeguard the reputation of the area, generate income, influences tourism development, and furnish high value-added products in the market compared to other extensive agriculture products; further, it increases employment in the area.

Other environmental services linked to pastoralism were mentioned, such as protecting forests from fire, forest vegetation improvements, grazing renovation, soil enrichment, erosion protection, etc. The respondents also indicated that breeders are not aware of the goods and services offered from their ecosystem and the reciprocal benefits they bring to the environment. The primary beneficiaries of pastoral goods and services were the breeding sector, the communities of these areas, and the agriculture sector. The products offered by pastoralism are linked to livestock production and dairy and organic fertilisers for the agriculture sector and grazing quality.
The results indicate low social capital stock in the area (Figure 2). About $57 \%$ of participants indicated that they would leave their farm in the care of family members, and $25 \%$ trusted their nearest neighbours; the remainder did not know how they would behave in such a situation, showing a narrow radius of trust. Regarding trust in institutions, 30\% of participants felt that the current economic situation would improve, while $70 \%$ perceived the contrary. Additionally, $70 \%$ of the respondents perceive the country's economic and political deterioration situation in the future, and 30\% did not know how to respond.

Regarding the perception of ES, the results indicate that most respondents consider that the pastoral ecosystem provides cultural and socio-economic services (Figure 3). The respondents disagreed with the statements that pastoral ES increases deforestation and pollution. Moreover, the breeders strongly favoured cultural ES such as tradition, image, and reputation. Socio-economic services, such as employment, income generation, and tourism development, were ranked second, ranking environmental services third. However, it is interesting to compare the ES within and between ES categories to understand the perceptions of identified pastoral ES.

When comparing ecological ES such as biodiversity conservation, carbon sequestration, fire prevention, etc., the Wilcoxon signed-rank mean paired t-test (pvalue $=(0.05)$ shows that participants did not differentiate between fire prevention and biodiversi- 


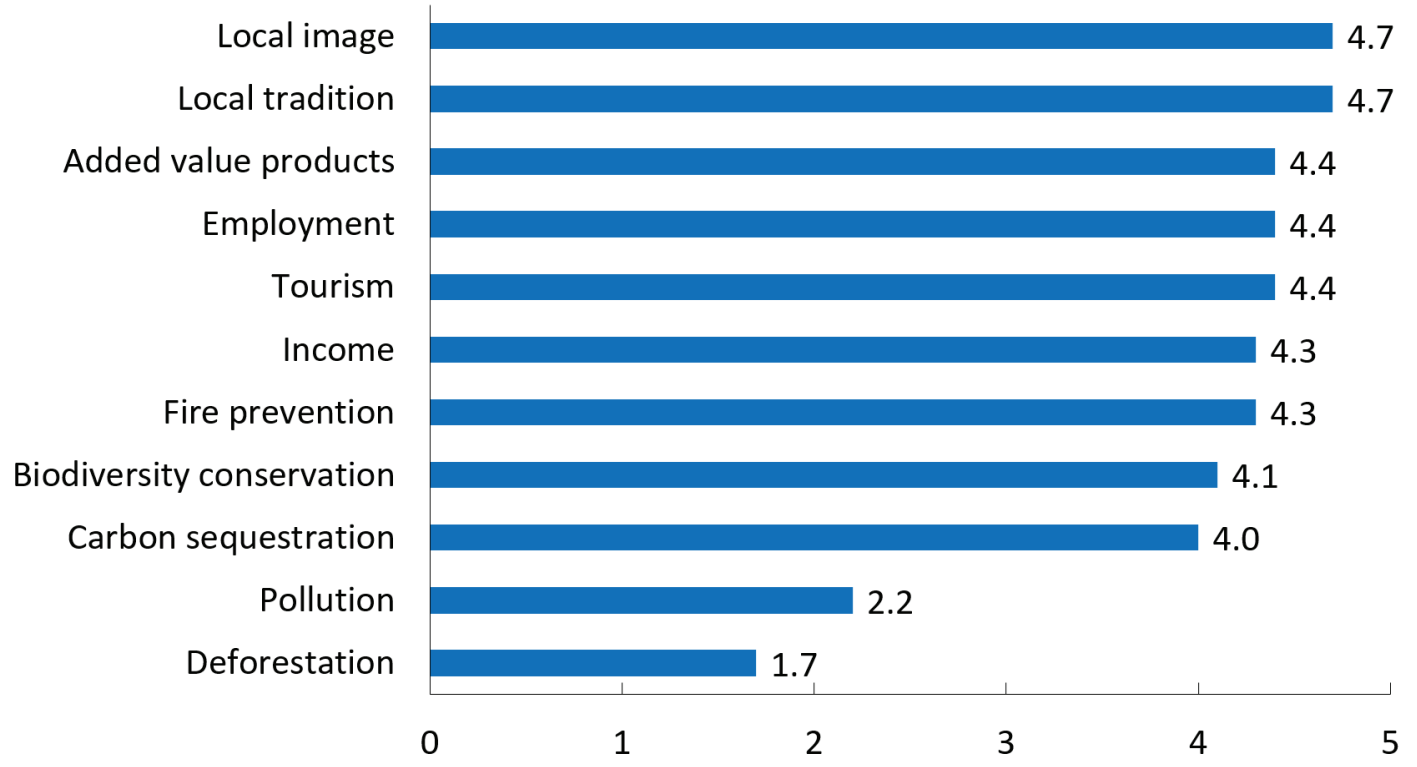

Figure 3. Pastoral ES perceptions

ty conservation by assigning the same importance score $(Z$ (value $)=-1.809 ; p$ (value $)=0.07$ ). While comparing fire prevention to carbon sequestration, the participants displayed a stronger inclination toward the first $(z$ (value $)=-3.651 ; p($ value $)=0.000)$ ). These results are linked to information clarity, as fire pre- vention is more explicit to breeders than biodiversity conservation or carbon sequestration. The lack of information about these services increases the difficulties encountered in channelling these services in future market transactions (i.e. PES). These results also reflect a typology of the pastoral ES in the area.

Table 3. Results of proportional odds model results linked to environmental ES provided by the pastoral ecosystem and social capital indicators.

\begin{tabular}{|c|c|c|c|c|c|c|c|c|}
\hline \multirow[t]{2}{*}{ SC Variables } & \multicolumn{2}{|c|}{ Deforestation } & \multicolumn{2}{|c|}{ Biodiversity } & \multicolumn{2}{|c|}{ Pollution } & \multicolumn{2}{|c|}{ Fire prevention } \\
\hline & $\beta$ & OR & $\beta$ & OR & $\beta$ & OR & $\beta$ & OR \\
\hline Trust 1 & $-20.334 * *$ & 0 & $-19.600 * *$ & 0 & -1.5326 & 0.216 & $-18.491 * *$ & 0 \\
\hline Trust 2 & -0.895 & 0.408 & 0.178 & 1.194 & 1.025 & 2.787 & -0.23 & 0.794 \\
\hline Trust 3 & 1.244 & 3.471 & -21.212 & 0 & $2.591^{*}$ & 13.345 & -18.176 & 0 \\
\hline CE1 & -17.93 & 0 & -0.097 & 0.907 & -18.752 & 0 & -1.976 & 0.139 \\
\hline CE2 & -0.404 & 0.668 & $-2.137^{*}$ & 0.118 & -0.047 & 0.954 & -0.82 & 0.44 \\
\hline CE3 & 1.348 & 3.85 & $1.537^{*}$ & 4.65 & $-1.342 * *$ & 0.261 & 0.292 & 1.339 \\
\hline CE4 & 0.517 & 1.676 & -0.295 & 0.745 & -0.305 & 0.737 & 0.142 & 1.152 \\
\hline CE5 & -1.041 & 0.353 & 0.401 & 1.493 & -0.2 & 0.818 & 0.153 & 1.165 \\
\hline CE6 & 1.053 & 2.868 & -0.209 & 0.811 & 0.759 & 2.136 & -1.074 & 0.342 \\
\hline CE7 & -0.064 & 0.938 & 0.938 & 2.556 & 0.034 & 1.034 & 0.797 & 2.218 \\
\hline CE8 & 0.227 & 1.255 & 0.956 & 2.6 & 0.756 & 2.129 & -0.107 & 0.899 \\
\hline CE9 & $-3.396 * *$ & 0.033 & -0.214 & 0.808 & $-1.735^{* *}$ & 0.176 & $2.026 * *$ & 7.584 \\
\hline CE10 & $2.340 * *$ & 10.379 & $-1.580 *$ & 0.206 & $1.591 * *$ & 4.906 & $-2.026 * *$ & 0.132 \\
\hline $\begin{array}{l}\text { Model fitting } \\
\text { parameters }\end{array}$ & \multicolumn{2}{|c|}{ Chi-Square $=46,173^{*}$} & \multicolumn{2}{|c|}{ Chi-Square $=56,677 *$} & \multicolumn{2}{|c|}{ Chi-Square $=40,216^{*}$} & \multicolumn{2}{|c|}{ Chi-Square $=38,770^{*}$} \\
\hline \multirow[t]{3}{*}{ Logit function } & \multicolumn{2}{|c|}{$R^{2}=0,41$} & \multicolumn{2}{|c|}{$R^{2}=0,47$} & \multicolumn{2}{|c|}{$R^{2}=0,36$} & \multicolumn{2}{|c|}{$\mathrm{R}^{2}=0,36$} \\
\hline & \multicolumn{2}{|c|}{ Test of parallel lines } & \multicolumn{2}{|c|}{ Test of parallel lines } & \multicolumn{2}{|c|}{ Test of parallel lines } & \multicolumn{2}{|c|}{ Test of parallel lines } \\
\hline & \multicolumn{2}{|c|}{ Chi-Square $=20,717^{\text {ns }}$} & \multicolumn{2}{|c|}{ Chi-Square $=8,448^{\text {ns }}$} & \multicolumn{2}{|c|}{ Chi-Square $=52,366^{\mathrm{ns}}$} & \multicolumn{2}{|c|}{ Chi-Square $=57,033^{n}$} \\
\hline
\end{tabular}

$\mathrm{P}=$ probability; $\mathrm{ns}=$ not significant $(\mathrm{P}>0.05) ;{ }^{*}=\mathrm{P}<0.05 ; * *=\mathrm{P}<0.01 ; * * *=\mathrm{P}<0.001$ 
Tradition conservation and good image/reputation achieve the highest score among all identified ES. Both show a significant statistical difference compared to all other considered ES. The comparison of the importance score attributed to carbon sequestration and income generation ( $Z$ (value)=-2.933; $p($ value $)=0.003), \quad$ employment $\quad(Z$ (value $)=-4.088$; $p$ (value) $=0.000$ ), and tourism development ( $Z$ (value) $=-4.208 ; p($ value $)=0.000)$ indicates that the participants attributed a higher score to socioeconomic services rather than carbon sequestration. The same results are observed when comparing the following biodiversity-income generation ( $Z$ (value)=-1.953; $\mathrm{p}$ (value) $=0.05)$, biodiversity-employment (Z(value)=-3.239; $p$ (value)=0.001), biodiversity-tourism development $(Z$ (value $)=-3.124 ; p($ value $)=0.002)$. The comparison of fire prevention with socio-economic services shows no difference between these (income generation, tourism development). That said, when employment is considered, fire prevention scored lower. These results show what is important to the participants from the pastoral community (breeders and cheese producers). The strong inclination towards cultural ES and socio-economic services in the pastoral area of Gjirokastra indicates a lack of awareness of the local community in the environmental aspects of their ecosystem. This information provides public policy and extension services insights about the best communication strategy for PES and their potential future implementation in Albania.

When considering the interaction between SC and $E S$, the importance of environmental-linked ES, the radius of trust (Trust1) and linking SC (CE10) show a significant effect (Table 3 ). Participants showing a higher Linking SC and higher radius of trust are more likely to attribute high importance scores than participants who do not display those features. The estimation of parameters shows that in deforestation, biodiversity conservation, and fire prevention services, participants showing a higher radius of trust are more likely to confer very high importance to these services (Table 3). Regarding CE indicators, respondents with links to important key persons in the public administration (Linking SC) and who have

Table 4. Results of proportional odds model results linked to Cultural ES provided by the pastoral ecosystem and social capital indicators.

\begin{tabular}{|c|c|c|c|c|c|c|}
\hline \multirow[b]{2}{*}{ Variables } & \multicolumn{2}{|c|}{ Tradition } & \multicolumn{2}{|c|}{ Image of the area } & \multicolumn{2}{|c|}{ High value-added products } \\
\hline & $\beta$ & Odds & $\beta$ & Odds & $\beta$ & Odds \\
\hline Trust 1 & $-20.946 * *$ & 0 & -18.563 & 0 & $-20.609 * *$ & 0 \\
\hline Trust 2 & $-22.253 * *$ & 0 & -21.539 & 0 & -1.415 & 0.243 \\
\hline Trust 3 & $-18.196 *$ & 0 & -18.006 & 0 & -17.905 & 0 \\
\hline CE1 & -3.199 & 0.041 & -20.854 & 0 & -2.089 & 0.124 \\
\hline CE2 & $-3.421 *$ & 0.033 & -19.868 & 0 & $-2.108 *$ & 0.121 \\
\hline CE3 & 1.694 & 5.442 & $-2.123 *$ & 0.12 & 0.244 & 1.276 \\
\hline CE4 & $2.165 *$ & 8.718 & 1.057 & 2.877 & -0.14 & 0.869 \\
\hline CE5 & -2.187 & 0.112 & 0.609 & 1.839 & -0.159 & 0.853 \\
\hline CE6 & $-2.923 *$ & 0.054 & $-3.540 *$ & 0.029 & -1.139 & 0.32 \\
\hline CE7 & $5.016 * *$ & 150.799 & $-2.948 *$ & 0.052 & 0.638 & 1.893 \\
\hline CE8 & 0.287 & 1.333 & 5.16 & 174.157 & -0.272 & 0.762 \\
\hline CE9 & 1.168 & 3.217 & 0.911 & 2.488 & $2.289 *$ & 9.864 \\
\hline CE10 & $-4.004 *$ & 0.018 & -1.035 & 0.355 & $-2.351^{*}$ & 0.095 \\
\hline Education & 1.232 & 3.427 & $-1.756^{*}$ & 0.173 & $2.416 *$ & 11.197 \\
\hline Age & -0.777 & 0.46 & $3.985^{*}$ & 53.804 & 0.972 & 2.643 \\
\hline \multirow{2}{*}{$\begin{array}{l}\text { Model fitting } \\
\text { parameters }\end{array}$} & \multicolumn{2}{|c|}{ Chi-Square $=52,226 * * *$} & \multicolumn{2}{|c|}{ Chi-Square $=41,855^{* *}$} & \multicolumn{2}{|c|}{ Chi-Square $=54,698^{*} *$} \\
\hline & \multicolumn{2}{|c|}{$\mathrm{R} 2=0,55$} & \multicolumn{2}{|c|}{$\mathrm{R}^{2}=0,50$} & \multicolumn{2}{|c|}{$R^{2}=0,49$} \\
\hline \multirow[t]{2}{*}{ Logit function } & \multicolumn{2}{|c|}{ Test of parallel lines } & \multicolumn{2}{|c|}{ Test of parallel lines } & \multicolumn{2}{|c|}{ Test of parallel lines } \\
\hline & \multicolumn{2}{|c|}{ Chi-Square $=9,989^{\text {ns }}$} & \multicolumn{2}{|c|}{ Chi-Square $=8,448^{\text {ns }}$} & \multicolumn{2}{|c|}{ Chi-Square $=27,6222^{\mathrm{ns}}$} \\
\hline
\end{tabular}


participated in municipality meetings are keener to consider that deforestation is not linked to pastoral activities. Concerning carbon sequestration, the odds of ranking high importance is greater within the cohort of participants that brought a problem to the attention of the media (CE3). Trust in institutions seems not to affect the community's behaviour towards the identified environmental linked ES.

Pro-traditional values of the pastoral community are highly affected by Trust-SC and Civic Engagement-SC indicators (Table 4). High levels of trust characterise participants assigning higher scores to the traditional values of their pastoral ecosystem. Also, participants displaying a high radius of trust and high trust in institutions tend to give a higher score to the traditional aspects of the ecosystem. Regarding CE-SC indicators, participants who 1 ) have been members of environmental associations (CE2), 2) had actively participated in an information campaign (CE4), 3) made a monetary donation helping people in difficulty (CE6), 4) contributed to a collective investment in the community (CE7), and 5) arrayed higher Link- ing SC (CE10) are more likely to assign a higher score to preserve traditions such as the main ES supplied by the pastoral ecosystem (see Table 4). The demographics do not affect the importance score assigned to this ES. Thus, both SC's cognitive and structural SC's forms affect the traditional aspect of the pastoral ecosystem.

The image and high reputation of the area is another identified service linked to the pastoral ecosystem. The demographics and CE-SC affect the importance score assigned to this service. Highly educated, younger participants who 1) had brought a problem to the attention of the media (CE3) and 2) who had donated to people in difficulty (CE6), 3) contributed in kind and 4) made collective investments are more likely to assign a higher score to the image of the area. These findings indicate that the youngest and most educated participants perceive higher pastoral ecosystem equity due to the competitive advantage conferred by the image of the pastoral geographical area.

Table 5. Results of proportional odds model results linked to socio-economic ES provided by the pastoral ecosystem and social capital indicators.

\begin{tabular}{|c|c|c|c|c|}
\hline ES & \multicolumn{2}{|c|}{ Incomes } & \multicolumn{2}{|c|}{ Employment } \\
\hline Variables & $\beta$ & Odds & $\beta$ & Odds \\
\hline Trust 1 & $-21.662 * *$ & 0 & $-20.229 * *$ & 0 \\
\hline Trust 2 & $-2.945^{*}$ & 0.053 & -1.322 & 0.267 \\
\hline Trust 3 & -18.166 & 0 & -17.74 & 0 \\
\hline CE1 & 1.862 & 6.435 & -1.301 & 0.272 \\
\hline CE2 & -1.307 & 0.271 & $-1.877^{*}$ & 0.153 \\
\hline CE3 & 0.342 & 1.407 & -0.273 & 0.761 \\
\hline CE4 & -1.102 & 0.332 & 0.227 & 1.255 \\
\hline CE5 & -1.483 & 0.227 & -0.488 & 0.614 \\
\hline CE6 & $-2.629 *$ & 0.072 & $-1.409 *$ & 0.245 \\
\hline CE7 & $2.433^{*}$ & 11.391 & $1.462 *$ & 4.313 \\
\hline CE8 & 0.89 & 2.436 & 0.584 & 1.793 \\
\hline CE9 & 0.751 & 2.12 & $1.701^{*}$ & 5.481 \\
\hline CE10 & $-2.223^{*}$ & 0.108 & $-2.347^{*}$ & 0.096 \\
\hline Education & 1.317 & 3.732 & 1.245 & 3.472 \\
\hline Age & -0.141 & 0.868 & 0.24 & 1.271 \\
\hline Model fitting parameters & \multicolumn{2}{|c|}{ Chi-Square $=53,848^{* *}$} & \multicolumn{2}{|c|}{ Chi-Square $=42,076 * *$} \\
\hline \multirow[t]{3}{*}{ Logit function } & \multicolumn{2}{|c|}{$R^{2}=0,48$} & \multicolumn{2}{|c|}{$\mathrm{R} 2=0,40$} \\
\hline & \multicolumn{2}{|c|}{ Test of parallel lines } & \multicolumn{2}{|c|}{ Test of parallel lines } \\
\hline & \multicolumn{2}{|c|}{ Chi-Square $=42,267^{\text {ns }}$} & \multicolumn{2}{|c|}{ Chi-Square $=32,301^{\mathrm{ns}}$} \\
\hline
\end{tabular}


Concerning the role of the pastoral ecosystem in generating incomes for the community, participants with a higher radius of trust and greater trust in actual institutions, who make donations, and investments to the community are more likely to assign higher importance to this aspect of the pastoral ecosystem (Table 5). Employment is another ES offered by pastoral activity. According to producers, pastoral activity is the main source of employment and influences agritourism development.

\section{Discussion}

A review of the perceptions of local people studies shows that there are four distinct categories of insights that studies of local perceptions can provide to improve conservation policy and practice: 1) social impacts of conservation, 2) ecological outcomes of conservation, 3) legitimacy of conservation and the 4) social acceptability of environmental management (Bennett, 2016). In the present research, we propose a baseline that considers a perceptual map on the importance of different ES identified in a particular territory. This type of analysis is a preliminary step in an ecosystem where de facto no conservation is available. The ecosystem stakeholders' perception analysis is the first step in every conservation strategy and practice since the innovations from the agroecology perspective need the application of participatory design processes. Indeed, four segments of stakeholders identified three types of $E S$, which might be enriched by three dimensions of SC, trust, CE and linking.

Although engaging in ES markets is not an easy task at the community level, significant barriers might include a lack of SC, no administrative capacity, and limited previous experience with market transactions. Despite these hurdles, participation (CE) and the linking SC effect in increasing awareness might be used to channel communication efforts towards environmental ES in the agropastoral ecosystem that can be facilitated by providing clear guidance on the management options that will yield payments, access to extensions and technical assistance, and capacity building for local institutions. As previously mentioned, Milder et al. (2010) estimate that low-in- come households could participate by 2030 in markets for biodiversity conservation, which could benefit 10-15 million people and carbon sequestration (25-50 million people). In this regard, the adapted replication of developed countries' frameworks may enable rural people to benefit from these instruments. Indeed, two patterns are observed from the analysis of the importance score of pastoral ES and the linkage with SC indicators. The first indicates that the importance scores of ES linked to the environment are generally affected by structural SC. In this respect, linking SC shows that people displaying this feature are more likely to assign higher importance to ecological ES, such as biodiversity conservation, carbon sequestration, and fire prevention. These findings demonstrate that participation, especially in CE activities, can play an important role in raising awareness of the importance of ES linked to the pastoral ecosystem.

Through participation, the suppliers of pastoral ES can access information regarding ES and existing PES schemes. Secondly, the cultural ES identified in this study relates to pastoral services, i.e., help maintain the tradition in the area and enhance the reputation and good image of the area; they are affected by cognitive and structural social capital. Participants showing a high ranking for SC (both types) are more likely to assign a higher importance score to the cultural pastoral ES. Moreover, young and well-educated participants offer higher scores to these services and consider the pastoral ecosystem the main component of creating a unique selling proposition for the area. These results are also in line with the consumer side (Imami et al., 2016; Kokthi et al., 2016; Kokthi \& Kruja, 2017a). The cultural ingredient of pastoral ES validates the socio-ecological feature and importance of human activity. This is evident in Mediterranean (developing) countries where cultural ES are more recognisable than environmental ES.

The increase of SC through the Linking dimension can enhance ES identification and development, not only those linked to traditional aspect, high value-added, image and reputation but also those linked to environment. The Linking dimension of SC can produce a snowball effect in recognising the typology of the ES through the dissemination of the information in both directions. To policymakers from 
one side and the stakeholders of the pastoral ecosystem. Also, the participants having a higher radius of trust and linking SC can play an important role in ES market anticipation. Furthermore, the pastoral ecosystem encompasses unique resources at the core of long-term future marketing through Origin Bounded Brand Equity (OBBE) (Kokthi \& Kruja, 2017b). The uniqueness of place and people applying traditional knowledge in a specific ecosystem gives birth to place food systems, including practices such as local branding, short food supply chains, geographic indications, etc. Plieninger et al. (2018) show that place food networks foster biocultural diversity in landscapes and CE plays a pivotal role. The authors mentioned above describe the biocultural dimension of ecosystems as conceptually emerging from an anthropological viewpoint in which human societies adapt to the diverse biological conditions in which they live.

Additionally, biocultural diversity is influenced by the relationship between traditional knowledge, biological diversity, and cultural diversity (Plieninger et al., 2018). In the present study, the tradition, image of the area, and value-added products are highly evaluated. In recent research developed in the same pastoral ecosystem, analysing the applicability of a place food system such as the Geographical Indications (GI) from the lenses of SC indicates that CE is pivotal in the future implementation of GI (Kokthi et al., 2021).

Moreover, high cultural values inherent in traditional food systems optimise the chances for vulnerable populations to adapt to changing conditions, and biodiversity can be conserved and enhanced through rational use within a broad-based developmental focus on small-scale and low-input production (Johns \& Sthapit, 2004). This study shows that agroecology principles might offer a potential scenario in the development of agropastoral areas, especially in countries with small size agriculture patterns such as Albania, where the development of agriculture cannot be based on an intensified productivist scenario.

In a nutshell, ES and SC interactions need further operationalisation that considers, at the same time, SC, agroecology and food place networks such as OBBE extended to environmental ecosystems services. Mutual consideration of biocultural diversity, food and environment can guide policy, research, integrated communications, and applied action in developing countries.

\section{Conclusions}

The analysis of pastoral community perceptions in the south of Albania on the ES provided by their ecosystem anticipates a clear categorisation of ES of cultural, ecological and socio-economic factors. Cultural ES, such as the conservation of tradition and image/reputation, scored higher than ecological services such as fire prevention, biodiversity, and carbon sequestration. These services are also scored higher when compared to economic services such as income generation, employment, and tourism development. These findings will help policymakers steer communication strategies towards awareness raising of existing environmental conservation schemes such as PES and the role of local institutions in the identification process of pastoral ES systems. In this regard, the concept of nature-based solutions could also apply to socio-ecological ecosystems, such as agropastoral ones; local communities could be reattributed for these solutions. Scientific research documenting the links between ecosystem functioning and human well-being can motivate demand for ES by helping prospective beneficiaries understand the importance of investing in such services.

\section{References}

Albaum, G. (1997). The Likert Scale Revisited. Market Research Society. Journal., 39(2), 1-21. DOI: $10.1177 / 147078539703900202$

Alló, M., Igleasias, E., Loureiro, M. L., Alló, M., Igleasias, E., \& Loureiro, M. L. (2013). Farmers' preferences and social capital towards agrienvironmental schemes for protecting birds. DOI: 10.22004/AG.ECON.150620

Alvarez, E. C., \& Romai, J. R. (2017). Measuring Social Capital: Further insights. Gaceta Sanitaria, 31(1), 57-61. 
Amézquita, M. C., Ibrahim, M., Llanderal, T., Buurman, P., \& Amézquita, E. (2004). Carbon Sequestration in Pastures, Silvo-Pastoral Systems and Forests in Four Regions of the Latin American Tropics. Journal of Sustainable Forestry, 21(1), 31-49. DOI: 10.1300/J091v21n01_02

Antle, J. M., \& Diagana, B. (2003). Creating Incentives for the Adoption of Sustainable Agricultural Practices in Developing Countries: The Role of Soil Carbon Sequestration. American Journal of Agricultural Economics, 85(5), 1178-1184. JSTOR.

Antle, J. M., \& Stoorvogel, J. J. (2008). Agricultural carbon sequestration, poverty, and sustainability. Environment and Development Economics, 13(3), 327-352. DOI: 10.1017/S1355770X08004324

Assouma, M. H., Lecomte, P., Corniaux, C., Hiernaux, P., Ickowicz, A., \& Vayssières, J. (2019). Territoires d'élevage pastoral au Sahel: Un bilan carbone avec un potentiel inattendu d'atténuation du changement climatique. Perspective, 52, 1-4. DOI: 10.19182/agritrop/00082

Barnaud, C., Corbera, E., Muradian, R., Salliou, N., Sirami, C., Vialatte, A., Choisis, J.-P., Dendoncker, N., Mathevet, R., Moreau, C., Reyes-García, V., Boada, M., Deconchat, M., Cibien, C., Garnier, S., Maneja, R., \& Antona, M. (2018). Ecosystem services, social interdependencies, and collective action. Ecology and Society, 23(1). JSTOR. URL: www.jstor.org/stable/26799064

Barnes-Mauthe, M., Oleson, K. L. L., Brander, L. M., Zafindrasilivonona, B., Oliver, T. A., \& van Beukering, P. (2015). Social capital as an ecosystem service: Evidence from a locally managed marine area. Ecosystem Services, 16, 283-293. DOI: 10.1016/j.ecoser.2014.10.009

Bennett, N. J. (2016). Using perceptions as evidence to improve conservation and environmental management: Perceptions and Conservation. Conservation Biology, 30(3), 582-592. DOI: 10.1111/cobi.12681

Berthet, E. T. A., Barnaud, C., Girard, N., Labatut, J., \& Martin, G. (2016). How to foster agroecological innovations? A comparison of participatory design methods. Journal of Environmental
Planning and Management, 59(2), 280-301. DOI: 10.1080/09640568.2015.1009627

Bigando, É., \& Charbonneau, M. (2017). Et si le paysage était au service de l'éleveur ?: Le rapport au paysage d'éleveurs de la montagne bascobéarnaise. Projets de Paysage, 17. DOI: 10.4000/ paysage. 4227

Bouma, J., Bulte, E., \& van Soest, D. (2008). Trust and cooperation: Social capital and community resource management. Journal of Environmental Economics and Management, 56(2), 155-166. DOI: 10.1016/j.jeem.2008.03.004

Brehm, J., \& Rahn, W. (1997). Individual-Level Evidence for the Causes and Consequences of Social Capital*. American Journal of Political Science, 41(3), 999.

Callois, J. M. (2004). SOCIAL CAPITAL AND LOCAL ECONO1VIIC DEVELOPMENT An applicaton to French rural areas. Revue D`Economie Regionale et Urbaine, 4, 551-578.

Callois, J. M., \& Aubert, F. (2007). Towards Indicators of Social Capital for Regional Development Issues: The Case of French Rural Areas. Regional Studies, 41(06), 809-821.

Cranford, M., \& Mourato, S. (2011). Community conservation and a two-stage approach to payments for ecosystem services. Ecological Economics, 71, 89-98. DOI: 10.1016/j. ecolecon.2011.08.007

Dong, S. (2016). Overview: Pastoralism in the World. In S. Dong, K.-A. S. Kassam, J. F. Tourrand, \& R. B. Boone (Eds.), Building Resilience of HumanNatural Systems of Pastoralism in the Developing World (pp. 1-37). Springer International Publishing. DOI: 10.1007/978-3-319-30732-9_1

Dong, S., Wen, L., Liu, S., Zhang, X., Lassoie, J. P., Yi, S., Li, X., Li, J., \& Li, Y. (2011). Vulnerability of Worldwide Pastoralism to Global Changes and Interdisciplinary Strategies for Sustainable Pastoralism. Ecology and Society, 16(2). JSTOR. URL: www.jstor.org/stable/26268902

Dumont, B., Ryschawy, J., Duru, M., Benoit, M., Chatellier, V., Delaby, L., Donnars, C., Dupraz, P., Lemauviel-Lavenant, S., Méda, B., Vollet, D., \& 
Sabatier, R. (2019). Review: Associations among goods, impacts and ecosystem services provided by livestock farming. Animal, 13(8), 1773-1784. DOI: $10.1017 /$ S1751731118002586

Fisher, B., Turner, R. K., \& Morling, P. (2009). Defining and classifying ecosystem services for decision making. Ecological Economics, 68(3), 643-653. DOI: 10.1016/j.ecolecon.2008.09.014

Gómez-Baggethun, E., de Groot, R., Lomas, P. L., \& Montes, C. (2010). The history of ecosystem services in economic theory and practice: From early notions to markets and payment schemes. Ecological Economics, 69(6), 1209-1218. DOI: 10.1016/j.ecolecon.2009.11.007

Graff-Zivin, J., \& Lipper, L. (2008). Poverty, risk, and the supply of soil carbon sequestration. Environment and Development Economics, 13(3), 353-373. DOI: 10.1017/S1355770X08004300

Hejnowicz, A. P., Raffaelli, D. G., Rudd, M. A., \& White, P. C. L. (2014). Evaluating the outcomes of payments for ecosystem services programmes using a capital asset framework. Ecosystem Services, 9, 83-97. DOI: 10.1016/j. ecoser.2014.05.001

Helliwell, J. F., \& Putnam, R. D. (1995). Economic Growth and Social Capital in Itali. Eastern Economic Journal, 3, 295-307.

Huntsinger, L., \& Oviedo, J. L. (2014). Ecosystem Services are Social\&\#8211;ecological Services in a Traditional Pastoral System: The Case of California\&\#8217;s Mediterranean Rangelands. Ecology and Society, 19(1), art8. DOI: 10.5751/ES06143-190108

Imami, D., Skreli, E., Zhllima, E., Canavari, M., Chan, C., \& Cela, A. (2016). Analysis of consumers' preferences for typical local cheese in Albania applying conjoint analysis. 3, 49-55.

Ishihara, H. (2018). Relational values from a cultural valuation perspective: How can sociology contribute to the evaluation of ecosystem services? Current Opinion in Environmental Sustainability, 35, 61-68. DOI: 10.1016/j. cosust.2018.10.016
Jenkins, M., Scherr, S. J., \& Inbar, M. (2004). Markets for Biodiversity Services: Potential Roles and Challenges. Environment: Science and Policy for Sustainable Development, 46(6), 32-42. DOI: 10.1080/00139157.2004.10545160

Johns, T., \& Sthapit, B. R. (2004). Biocultural Diversity in the Sustainability of Developing-Country Food Systems. Food and Nutrition Bulletin, 25(2), 143155. DOI: $10.1177 / 156482650402500207$

Kenter, J. O., O’Brien, L., Hockley, N., Ravenscroft, N., Fazey, I., Irvine, K. N., Reed, M. S., Christie, M., Brady, E., Bryce, R., Church, A., Cooper, N., Davies, A., Evely, A., Everard, M., Fish, R., Fisher, J. A., Jobstvogt, N., Molloy, C., ... Williams, S. (2015). What are shared and social values of ecosystems? Ecological Economics, 111, 86-99. DOI: 10.1016/j. ecolecon.2015.01.006

Kokthi, E., Bermúdez, I. V., \& Limón, M. G. (2016). Predicting willingness to pay for geographical origin in Albania: A logistic approach. New Medit, 15(2), 63-69.

Kokthi, E., Guri, G., \& Muco, E. (2021). Assessing the applicability of geographical indications from the social capital analysis perspective: Evidences from Albania. Economics \& Sociology, 14(3), 3253. DOI: 10.14254/2071-789X.2021/14-3/2

Kokthi, E., \& Kruja, D. (2017a). Consumer Expectations for Geographical Origin: Eliciting Willingness to Pay (WTP) Using the Disconfirmation of Expectation Theory (EDT). Journal of Food Products Marketing, 23(8), 873-889. DOI: 10.1080/10454446.2017.1244794

Kokthi, E., \& Kruja, D. (2017b). Customer Based Brand Equity Analysis: An Empirical Analysis to Geographical Origin. 171.

Kokthi, E., Limon, M. G., \& Isabel Vazquez Bermudez. (2015). Origin or food safety attributes? Analyzing consumer preferences using Likert Scale. Empirical evidence from Albania. New Medit, 14(4), 50-58.

Krishna, A., \& Uphoff, N. (1999). Mapping and measuring social capital: A conceptual and empirical study of collective action for conserving and developing watersheds in Rajasthan, India. World Bank,Social Development Family, 
Environmentally and Socially Sustainable Development Network.

McGrath, F. L., Erbaugh, J. T., Leimona, B., Amaruzaman, S., Rahadian, N. P., \& Carrasco, L. R. (2018). Green without envy: How social capital alleviates tensions from a Payments for Ecosystem Services (PES) program in Indonesia. Ecology and Society, 23(4). DOI: 10.5751/ES-10181-230410

McCullagh, P., and J. A. Nelder. (1989). Generalized Linear Models, 2nd ed. London: Chapman \& Hall.

Milder, J. C., Scherr, S. J., \& Bracer, C. (2010). Trends and Future Potential of Payment for Ecosystem Services to Alleviate Rural Poverty in Developing Countries. Ecology and Society, 15(2). JSTOR. URL: www.jstor.org/stable/26268124

Nagelkerke, N. J. D. (1991). A note on the general definition of the coefficient of determination. Biometrika, 78:3, 691-692.

Niamir-Fuller, M., Kerven, C., Reid, R., \& MilnerGulland, E. (2012). Co-existence of wildlife and pastoralism on extensive rangelands: Competition or compatibility? Pastoralism: Research, Policy and Practice, 2(1), 8. DOI: 10.1186/2041-7136-28

Notaro, S., \& Paletto, A. (2011). Links between Mountain Communities and Environmental Services in the Italian Alps. 51(2).

Pascual, U., Phelps, J., Garmendia, E., Brown, K., Corbera, E., Martin, A., Gomez-Baggethun, E., \& Muradian, R. (2014). Social Equity Matters in Payments for Ecosystem Services. BioScience, 64(11), 1027-1036. DOI: 10.1093/biosci/biu146

Plieninger, T., Kohsaka, R., Bieling, C., Hashimoto, S., Kamiyama, C., Kizos, T., Penker, M., Kieninger, P., Shaw, B. J., Sioen, G. B., Yoshida, Y., \& Saito, O. (2018). Fostering biocultural diversity in landscapes through place-based food networks: A "solution scan" of European and Japanese models. Sustainability Science, 13(1), 219-233. DOI: $10.1007 / s 11625-017-0455-z$

Pretty, J., \& Ward, H. (2001). Social Capital and the Environment. World Development, 29(2), 209227. DOI: 10.1016/S0305-750X(00)00098-X
Putnam, R. (2000). Bowling Alone: America's Declining Social Capital. Culture and Politics, 223234.

Raymond, C. M., Kenter, J. O., Plieninger, T., Turner, N. J., \& Alexander, K. A. (2014). Comparing instrumental and deliberative paradigms underpinning the assessment of social values for cultural ecosystem services. Ecological Economics, 107, 145-156. DOI: 10.1016/j. ecolecon.2014.07.033

Reed, M. S., Allen, K., Attlee, A., Dougill, A. J., Evans, K. L., Kenter, J. O., Hoy, J., McNab, D., Stead, S. M., Twyman, C., Scott, A. S., Smyth, M. A., Stringer, L. C., \& Whittingham, M. J. (2017). A place-based approach to payments for ecosystem services. Global Environmental Change, 43, 92-106. DOI: 10.1016/j.gloenvcha.2016.12.009

Scoones, I., \& Graham, O. (1994). New directions for pastoral development in Africa. Development in Practice, 4(3), 188-198. DOI: $10.1080 / 096145249100077821$

Seid, M. A., Kuhn, N. J., \& Fikre, T. Z. (2016). The role of pastoralism in regulating ecosystem services: -EN- -FR- Le rôle du pastoralisme dans la réglementation des services écosystémiques -ES- La función del pastoreo en la regulación de los servicios ecosistémicos. Revue Scientifique et Technique de I'OIE, 35(2), 435-444. DOI: 10.20506/rst.35.2.2534

Seppelt, R., Dormann, C. F., Eppink, F. V., Lautenbach, S., \& Schmidt, S. (2011). A quantitative review of ecosystem service studies: Approaches, shortcomings and the road ahead: Priorities for ecosystem service studies. Journal of Applied Ecology, 48(3), 630-636. DOI: 10.1111/j.13652664.2010.01952.x

Tamou, C., de Boer, I. J. M., Ripoll-Bosch, R., \& Oosting, S. J. (2018). Traditional ecological knowledge underlying herding decisions of pastoralists. Animal, 12(4), 831-843. DOI: $10.1017 /$ S1751731117002130

Thuy, N. N., Dwivedi, P., Rossi, F., Alavalapati, J. R. R., \& Thapa, B. (2011). Role of social capital in determining conservation attitude: A case study from Cat Tien National Park, Vietnam. 
International Journal of Sustainable Development \& World Ecology, 18(2), 143-153. DOI: 10.1080/13504509.2011.560455

Villalonga-Olives, E., Adams, I., \& Kawachi, I. (2016). The development of a bridging social capital questionnaire for use in population health research. SSM - Population Health, 2, 613-622. DOI: 10.1016/j.ssmph.2016.08.008

Villalonga-Olives, E. \& Kawachi, I. (2017). The dark side of social capital: A systematic review of the negative health effects of social capital. Social Science and Medicine, 194, 105-127.

Welter, F. (2012). All we need is trust? A critical review of the trust and entrepreneurship literature. International Small Business Journal, 30(3), 193-212. 